\title{
The L-type calcium channel in the heart: the beat goes on
}

\author{
Ilona Bodi, Gabor Mikala, Sheryl E. Koch, Shahab A. Akhter, and Arnold Schwartz
}

\author{
Institute of Molecular Pharmacology and Biophysics, University of Cincinnati College of Medicine, Department of Surgery, Cincinnati, Ohio, USA.
}

\begin{abstract}
Sydney Ringer would be overwhelmed today by the implications of his simple experiment performed over 120 years ago showing that the heart would not beat in the absence of $\mathrm{Ca}^{2+}$. Fascination with the role of $\mathrm{Ca}^{2+}$ has proliferated into all aspects of our understanding of normal cardiac function and the progression of heart disease, including induction of cardiac hypertrophy, heart failure, and sudden death. This review examines the role of $\mathrm{Ca}^{2+}$ and the L-type voltage-dependent $\mathrm{Ca}^{2+}$ channels in cardiac disease.
\end{abstract}

When Sydney Ringer (1) discovered the vital role of $\mathrm{Ca}^{2+}$ in the heart, investigations took a leap forward and have continued unabated (2). Austrian scientist Otto Loewi, best known for his work on autonomic transmitters and discovery of "chemical vagusstoff," recognized the connection between digitalis and $\mathrm{Ca}^{2+}$ in 1917-1918. Although he always believed that $\mathrm{Ca}^{2+}$ was the key to understanding life's processes, the Nobel Prize in Physiology and Medicine was awarded to Loewi and Sir Henry Hallett Dale in 1936 for their studies on neurotransmitters.

$\mathrm{Ca}^{2+}$ is the link in excitation-contraction (EC) coupling (Figure 1), which starts during the upstroke of the action potential (AP) and causes the opening of the L-type voltage-dependent $\mathrm{Ca}^{2+}$ channel (L-VDCC). Interest in high-voltage-activated L-VDCCs began with biochemical and continued with molecular characterizations, culminating in the cloning of the pore-forming $\alpha_{1}$ subunit and the auxiliary channel subunit $\alpha_{2} / \delta$ from rabbit skeletal muscle (3-5). Although the L-VDCC subunits are most abundant in fast skeletal transverse tubules, $\mathrm{Ca}^{2+}$ influx is not required for contraction in skeletal muscle, unlike cardiac muscle, which requires $\mathrm{Ca}^{2+}$ entry with each beat and triggers $\mathrm{Ca}^{2+}$ release from the sarcoplasmic reticulum (SR) via $\mathrm{Ca}^{2+}$-release channels, e.g., ryanodine receptor 2 (RyR2). This amplifying process, termed $\mathrm{Ca}^{2+}$-induced $\mathrm{Ca}^{2+}$ release (CICR) by A. Fabiato, causes a rapid increase in intracellular $\mathrm{Ca}^{2+}$ concentration $\left(\left[\mathrm{Ca}^{2+}\right]_{\mathrm{i}}\right)$ (from $\sim 100 \mathrm{nM}$ to $\left.\sim 1 \mu \mathrm{M}\right)$ to a level required for optimal binding of $\mathrm{Ca}^{2+}$ to troponin $\mathrm{C}$ and induction of contraction (2). There is a close correlation between activation of the L-type $\mathrm{Ca}^{2+}$ current $\left(I_{\mathrm{Ca}, \mathrm{L}}\right)$ and cardiac contraction. Contraction is followed by $\mathrm{Ca}^{2+}$ release from troponin $\mathrm{C}$ and its reuptake by the SR via activation of the SR $\mathrm{Ca}^{2+}$-ATPase 2 a (SERCA2a) $\mathrm{Ca}^{2+}$ pump in addition to extrusion across the sarcolemma via the $\mathrm{Na}^{+} / \mathrm{Ca}^{2+}$

Nonstandard abbreviations used: ACE, angiotensin-converting enzyme; AF, atrial fibrillation; AID, $\alpha$-interaction domain; AP, action potential; $\beta$-AR, $\beta$-adrenergic receptor; BID, $\beta$-interaction domain; BTZ, benzothiazepine; $\left[\mathrm{Ca}^{2+}\right]_{i}$, intracellular $\mathrm{Ca}^{2+}$ concentration; CaM, calmodulin; CaMKII, $\mathrm{Ca}^{2+} /$ calmodulin-dependent protein kinase II; $\mathrm{CCB}, \mathrm{Ca}^{2+}$ channel-blocker; $\mathrm{CDI}, \mathrm{Ca}^{2+}$-dependent inactivation; CREB, cAMP-responsive element-binding protein; DHP, dihydropyridine; EC, excitation-contraction; $I_{C a}, \mathrm{Ca}^{2+}$ current; $I_{C a, L}$, L-type $\mathrm{Ca}^{2+}$ current; IQ, isoleucine-glutamine; L-VDCC, L-type voltage-dependent $\mathrm{Ca}^{2+}$ channel; $\mathrm{NCX}, \mathrm{Na}^{+} / \mathrm{Ca}^{2+}$ exchanger; PAA, phenylalkylamine; PKA, protein kinase A; RyR2, ryanodine receptor 2 (cardiac); SH3-GK; Src homology 3-guanylate kinase; SR, sarcoplasmic reticulum; VDCC, voltage-dependent $\mathrm{Ca}^{2+}$ channel; VDI, voltage-dependent inactivation; VF, ventricular fibrillation.

Conflict of interest: The authors have declared that no conflict of interest exists.

Citation for this article: J. Clin. Invest. 115:3306-3317 (2005).

doi:10.1172/JCI27167. exchanger (NCX). In the human heart under resting conditions, the time required for cardiac myocyte depolarization, $\mathrm{Ca}^{2+}$ induced $\mathrm{Ca}^{2+}$ release, contraction, relaxation, and recovery is $600 \mathrm{~ms}$. This process occurs approximately 70 times a minute or over 2 billion times in the average lifespan. $\mathrm{Ca}^{2+}$ is also required for maintenance of cell integrity and gene expression (6) relevant to the growth and development of the embryonic heart (7). L-VDCCs are regulated by the adrenergic nervous system and may interact with $G$ protein-coupled receptors (8).

\section{Cardiac L-VDCC structure}

The L-VDCCs are heterotetrameric polypeptide complexes comprising the $\alpha_{1}, \alpha_{2} / \delta, \beta$, and, in some tissues, $\gamma$ subunits (Figure 2 ) that allow depolarization-induced calcium influx into the cytosol. In all excitable tissues, $\mathrm{Ca}^{2+}$ channels invariably contain $\alpha_{1}$, $\alpha_{2} / \delta$, and $\beta$ subunits. These are considered the functional minimum core for $\mathrm{Ca}^{2+}$ channel assembly. The accessory subunits $\left(\beta, \alpha_{2} / \delta\right)$ are tightly but not covalently bound to the $\alpha_{1}$ subunit and modulate the biophysical properties and trafficking of the $\alpha_{1}$ subunit to the membrane.

\section{$\alpha_{1}$ subunits}

The $\mathrm{Ca}^{2+}$ channel $\alpha_{1}$ subunit (170-240 kDa) consists of 4 homologous motifs (I-IV), each composed of 6 membrane-spanning $\alpha$-helices (termed S1 to S6) linked by variable cytoplasmic loops (linkers) between the S5 and S6 segments (Figure 2). To date, $10 \alpha_{1}$ subunit genes have been identified and separated into 4 classes: $\mathrm{Ca}_{\mathrm{v}} 1.1\left(\alpha_{1 \mathrm{~S}}\right), 1.2\left(\alpha_{1 \mathrm{C}}\right), 1.3\left(\alpha_{1 \mathrm{D}}\right)$, and $1.4\left(\alpha_{1 \mathrm{~F}}\right)$. Only the $\alpha_{1 \mathrm{C}}$ (dihydropyridine-sensitive [DHP-sensitive]) subunit is expressed in high levels in cardiac muscle. $\mathrm{Ca}_{\mathrm{v}} 2.1\left(\alpha_{1 \mathrm{~A}}\right), 2.2$ $\left(\alpha_{1 \mathrm{~B}}\right)$, and $2.3\left(\alpha_{1 \mathrm{E}}\right)$ form P/Q-, N-, and possibly R-type channels, respectively, and are all found in brain. They are primarily responsible for initiation of synaptic transmission at fast synapses in the nervous system. They have a larger intracellular loop connecting domains II and III, which contains a synaptic protein interaction site that binds SNARE proteins involved in exocytosis (9). $\mathrm{Ca}_{\mathrm{v}} 3.1\left(\alpha_{1 \mathrm{G}}\right), 3.2\left(\alpha_{1 \mathrm{H}}\right)$, and $3.3\left(\alpha_{1 \mathrm{I}}\right)$ form T-type channels that are localized to the brain, kidney, and heart and were originally called low-voltage-activated channels. Unlike L-type channels, they are relatively insensitive to DHPs. $\mathrm{Ca}_{\mathrm{v}} 3$ channels conduct $\mathrm{T}$-type $\mathrm{Ca}^{2+}$ currents, which are important in a wide variety of physiological functions, including neuronal firing, hormone secretion, smooth muscle contraction, cell proliferation of some cardiac tissue, and myoblast fusion. In the 


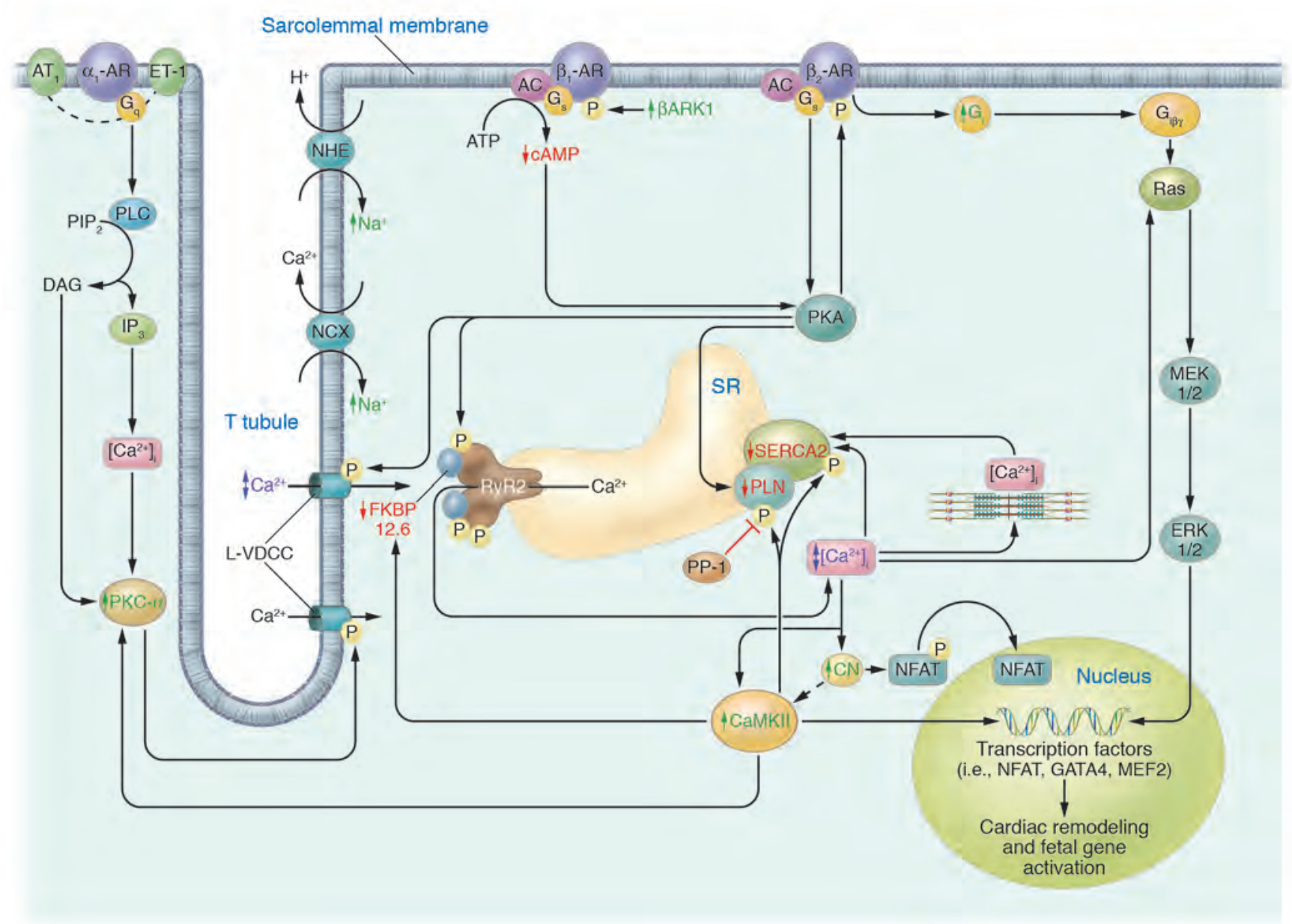

Figure 1

A model illustrating the $\mathrm{Ca}^{2+}$ signaling pathways implicated in hypertrophy and heart failure. Stimulation of the $\beta_{1}-A R$ activates $G_{s}$ (stimulatory G protein), which activates adenylyl cyclase (AC), causing production of cAMP. This stimulates cAMP-dependent PKA, which phosphorylates $(\mathrm{P})$ and alters the function of numerous substrates important for $\mathrm{SR} \mathrm{Ca}{ }^{2+}$ regulation, including the L-VDCC, RyR2, and phospholamban (PLN). $\beta_{2}$-ARs couple $G_{i} /$ Ras/MEK1/2/ERK1/2 pathways to hypertrophy $\left(G_{i}\right.$, inhibitory $G$ protein; $M E K 1 / 2$, mitogen-activated protein kinase kinase). Subsequently, the activated $\beta_{1}$-AR is desensitized when it is phosphorylated by $\beta$-AR kinase- 1 ( $\beta$ ARK 1 ). During hypertrophy, $\beta_{1}-A R$ expression increases. In heart failure, while the levels of PLN protein expression remain unchanged (or decreased), the phosphorylation status at Ser16 and Thr17 is decreased, even though the levels of SR Ca ${ }^{2+}$-ATPase 2a (SERCA2a) are decreased. Cardiac SR-associated protein phosphatase-1 (PP-1) removes phosphate at Ser16 in PLN and is upregulated in heart failure. Calstabin2 (FKB12.6) plays a role in stabilizing RyR2 in order to help maintain the channel in a closed state during diastole. RyR2 is hyperphosphorylated in heart failure, and calstabin2 dissociates from RyR2. Elevated NCX is an adaptive change in heart failure that becomes maladaptive and may be responsible for both arrhythmogenesis and contractile dysfunction. PKC- $\alpha$ expression and activity are elevated in heart failure. Calcineurin (CN) is activated by sustained elevation of $\left[\mathrm{Ca}^{2+}\right]_{\mathrm{i}}$. It dephosphorylates nuclear factor of activated T cells (NFAT), enabling its translocation to the nucleus, which is sufficient to induce hypertrophy. Hypertrophic stimuli, such as $\alpha_{1}$-adrenergic agonists, Ang II, and endothelin-1 (ET-1), all elevate [Ca $\left.{ }^{2+}\right]_{i}$ and activate the CN-NFAT, $\mathrm{Ca}^{2+} / \mathrm{CaM}-\mathrm{CaMKII}$, and PKC-MAPK-NFAT signaling systems through G protein-coupled receptors (GPCRs) and PLC-DAG-IP ${ }_{3}-$ dependent $\mathrm{Ca}^{2+}$ release [PLC, phospholipase C; DAG, diacylglycerol, $\mathrm{IP}_{3}$, inositol $(1,4,5)$-trisphosphate]. Transcription factors, such as myocyte-enhancer factor 2 (MEF2) and GATA4 (cardiac zinc finger transcription factor) are located in the nucleus and serve as endpoints for hypertrophic-signaling pathways. $A T_{1}$, type 1 angiotensin II receptors; $G_{i \beta \gamma}, \beta \gamma$ subunit of the activated $G_{i}$-binding protein; $G_{q}$, heterotrimeric GTP-binding protein, consisting of $\mathrm{G}_{\alpha}$ and $\mathrm{G}_{\beta \gamma}$, which dissociate upon receptor activation; $\mathrm{NHE}, \mathrm{Na}^{+} / \mathrm{H}^{+}$exchanger, regulates cytosolic $\mathrm{pH}$; $\mathrm{PIP}$, phosphatidylinositol 4,5-biphosphate; $T$ tubule, transverse tubule.

heart, T-type channels are abundant in sinoatrial pacemaker cells and Purkinje fibers of many species and are important for maintenance of pacemaker activity by setting the frequency of AP firing. T-type channels have been shown to be reexpressed in the ventricles of some animal models of heart failure, suggesting that T-type channels play a role in cardiac disease. The neuronal T-type channels can generate low-threshold spikes that lead to firing bursts and oscillations that are prominent in the thalamus and implicated in a variety of neurological disorders (10). In addition to these well characterized $\mathrm{Ca}^{2+}$ channels, the cloning of a single $\mathrm{Ca}_{\mathrm{v}}$-like protein in 1999 suggested the existence of a fourth subfamily (11). This novel protein contains conserved amino acids found in $\mathrm{Ca}^{2+}$ (EEEE) or $\mathrm{Na}^{+}$channels (DEKA), including EEKE residues in the corresponding 


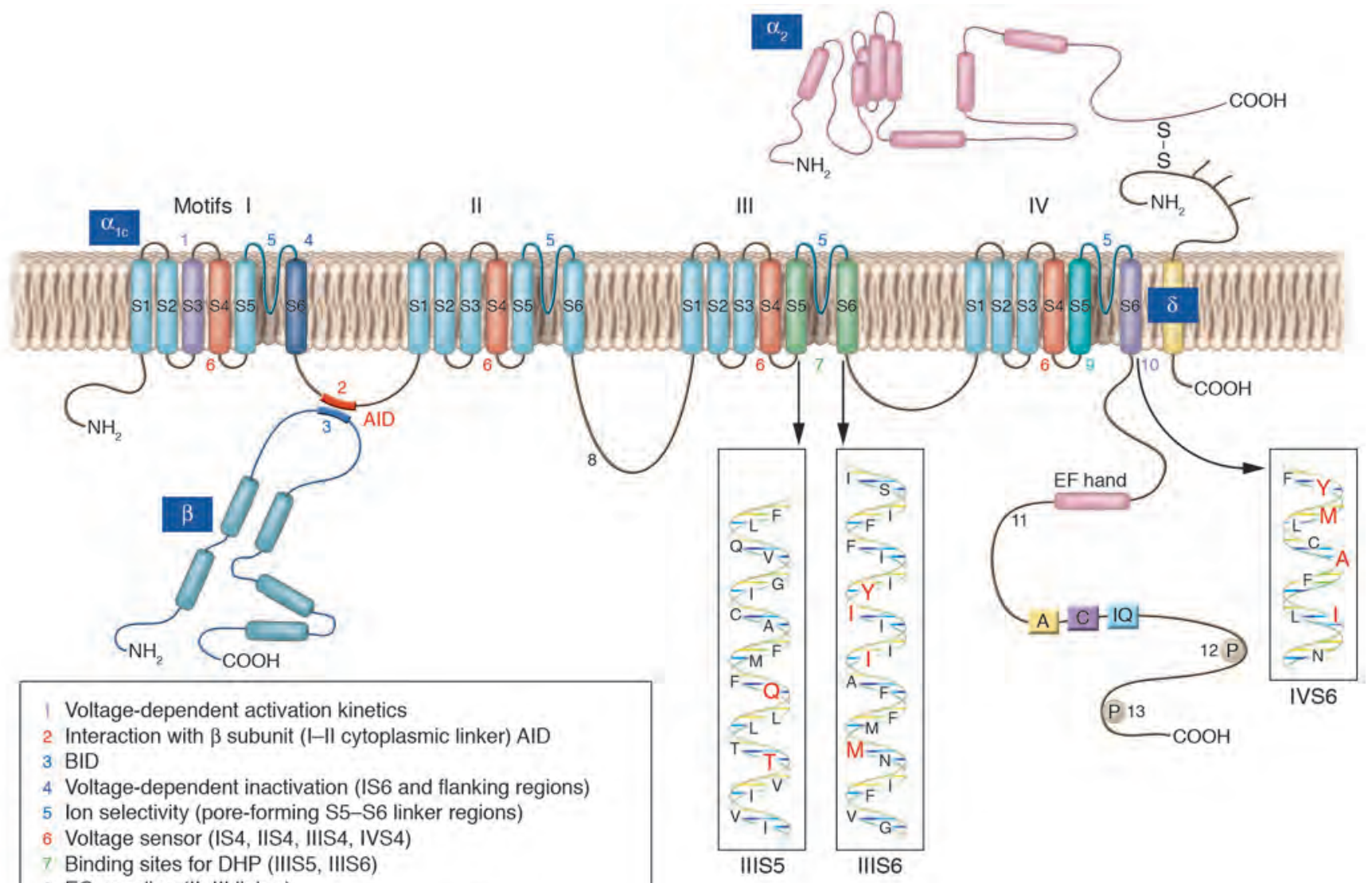

Figure 2

Structural organization of L-VDCCs. The predicted membrane topological organization of the core subunits, their interactions, and structural domains of the auxiliary subunits, which are common to all VDCC types, are shown. The primary structure of the pore-forming $\alpha_{1}$ subunit is composed of 4 homologous repeating motifs (I-IV), each of which consists of 6 putative transmembrane segments (S1-S6). The cytoplasmic loops are named according to the motifs they link. The $\alpha_{2} \delta$ and $\gamma$ (not shown in the Figure) subunits contain transmembrane domains whereas the $\beta$ subunit is entirely intracellular. Sites of interaction between subunits are indicated. The numbers point to areas found to be important for specific channel functions. The EF hand, A, C, and IQ motifs represent specific peptide sequences involved in CaM binding. Key amino acids required for $\mathrm{Ca}^{2+}$ antagonist binding are represented in red letters. At least 5 consensus sites for phosphorylation by cAMPdependent PKA have been discovered within the $C$ terminal tail of $\alpha_{1 \mathrm{C}}$. AKAP79 (79 kDa A-kinase-anchoring protein) helps to target PKA to its specific substrate. $\mathrm{COOH}$, carboxyterminal.

region of its pore loops. However, the authors were unable to functionally express this new putative channel in a heterologous expression system (Xenopus laevis oocyte).

The $\alpha_{1}$ subunit harbors the ion-selective pore, voltage sensor, gating machinery, and the binding sites for channel-modulating drugs $(2,5,12)$ and is autoregulatory. The pore is asymmetric, with conserved glutamate residue (EEEE) (or aspartate residue, in some positions in low voltage-activated channels) comprising the ion-selectivity filter(s) (13-16), located between segments S5 and S6 of each motif (Figure 2). Cloning and analysis of the VDCC have revealed that the positively charged fourth transmembrane segment (S4) of each motif is highly conserved and is likely to form an $\alpha$-helix in which every third or fourth residue is basic (Arg or Lys). It is thought that the $\mathrm{S} 4 \alpha$-helices traverse the membrane electric field and, in response to a depolarizing stimulus, move outward into the extracellular space, initiating conformational changes from nonconducting to conducting states of the channel (sliding-helix model) (reviewed in ref. 17). However, the emerging models are still controversial. Most structure-function studies support a spiral or rotational motion of the S4 or S3 plus $\mathrm{S} 4 \alpha$-helices through the channel protein in order to move gating charges across the membrane electric field. In contrast, Jiang et al. (18), on the basis of the crystal structure of the Aeropyrum pernix $\mathrm{K}^{+}$channel, proposed a model involving positively 
charged "voltage-sensor paddles" (each S4 segment forms half of a voltage-sensor paddle), which are located near the intracellular membrane surface at negative resting membrane potentials. In response to depolarization, the voltage-sensor paddles move through the lipid membrane bilayer to their external position, opening the pore by pulling on the S4-S5 linker. According to this model, the charged residues of $\mathrm{S} 4$ are not exposed to the intracellular solution at all, based on the finding that the S3B-S4 loop is not accessible to site-specific Fab fragments. However, this model does not explain how the voltage-sensor paddle of an ion channel operates in transporting positive charges across the lipid membrane. Starace and Bezanilla argued against this model (19), pointing out several discrepancies. They suggested a "proton pore" model in a $\mathrm{K}^{+}$channel voltage sensor, demonstrating that replacement of the first S4 arginine by histidine in the Shaker $\mathrm{K}^{+}$channel creates a proton pore when the cell is hyperpolarized. Proton transport occurs when depolarization of the membrane moves histidine residues coupled to the voltage sensor from the internal to external phase. Their model, in contrast to Jiang's model, shows that a small conformational change can transfer charges across the focused transmembrane field. Compelling experimental evidence from both models put the readers in a position to decide which model is favorable.

\section{Accessory subunits}

\section{$\alpha_{2} / \delta$ subunits}

The $\alpha_{2} \delta$ subunits are closely associated with the $\alpha_{1}$ subunit by surface interaction and are intracellularly linked through a disulfide bridge to a small protein, the $\delta$ subunit. The $\alpha_{2}$ subunit is entirely extracellular, and the $\delta$ subunity has a single transmembrane region with a very short intracellular part. The $\alpha_{2}$ and $\delta$ subunits are encoded by the same gene, which is separated by proteolytic cleavage (20). Ellis et al. (3) first cloned the $\alpha_{2} / \delta$ subunit from rabbit skeletal muscle, thinking there was only one product from the gene. Presently, at least 4 isoforms encoded by separate genes have been identified $\left(\alpha_{2} / \delta_{1,2,3,4}\right)(20-22)$. The issue of in vivo structure-function has yet to be resolved. In heterologous expression systems, coexpression of the $\alpha_{2} / \delta$ subunit affects $\alpha_{1}$ function by increasing channel density, charge movement, and $B_{\max }$ of drug binding (e.g., the DHP isradipine) with smaller effects on $K_{D}$ and variable minor effects on channel kinetics (refs. 4, 23, 24, and references therein). It is probable that the $\alpha_{2} / \delta$ and $\beta$ subunits "drive" the $\alpha_{1}$ subunit to the membrane in the correct insertion mode. The $\alpha_{2} / \delta_{1}$ subunit is ubiquitously distributed and possesses a stereo-selective high-affinity binding site for certain GABA-antagonists, such as the drug gabapentin, which is widely used to treat epilepsy, pain, sleep disorders, and many other paroxysmal neurological conditions (25-27). The $\alpha_{2} / \delta_{2}$ subunit also binds gabapentin but at low affinity while $\alpha_{2} / \delta_{3}$ and $\alpha_{2} / \delta_{4}$ do not bind this drug. Mice deficient in $\alpha_{2} / \delta_{2}$ exhibit neurological dysfunction, such as enhanced seizure susceptibility and cardiac abnormalities, namely a tendency to develop bradycardia (28). The recently cloned human $\alpha_{2} / \delta_{4}$ subunit (21) is localized to fetal liver, colon, pituitary, and adrenal gland and is associated with the $\alpha_{1 \mathrm{C}}$ subunit $\left(\mathrm{Ca}_{\mathrm{v}} 1.2\right)$ and the $\beta_{3}$ subunit. This reinforces the complexity of L-VDCCs since subunit association appears to confer biophysical properties (13, 23). This rich diversity opens avenues for exciting physiological and pathological discoveries (29).

\section{The $\gamma$ subunits}

It was originally thought that the $\gamma$ subunit was the product of a single gene and only existed in skeletal muscle (22). It is interesting that characterization of a genetic defect that induces epileptic seizures in stargazer mice (30) led to the detection of a family of at least 5 novel isoforms of the $\gamma$ subunit that are almost exclusively expressed in the brain. To date, 8 genes encoding a variety of $\gamma$ subunit isoforms have been identified (31). Although the $\gamma_{1}$ subunit is associated specifically with skeletal muscle $\mathrm{Ca}_{\mathrm{v}} 1.1$ channels, there is evidence that the $\gamma_{2}$ subunit interacts with $\alpha$-amino-3-hydroxy-5-methyl-4-isoxazole-propionic acid (AMPA) receptor subunits (30) and possibly other membranesignaling proteins. Unlike other auxiliary subunits ( $\beta$ and $\alpha_{2} \delta$ ), the $\gamma$ subunits do not have a significant role in the membrane trafficking of the $\mathrm{Ca}^{2+}$ channels. The $\gamma_{1}$ subunit modulates the biophysical properties of the $\mathrm{Ca}^{2+}$ channel. Clearly, this is a very important $\mathrm{Ca}^{2+}$ channel subunit, but since it does not appear to be expressed in heart, it is not discussed further here.

\section{$\beta$ subunit structure}

Four $\beta$ subunit isoforms $\left(\beta_{1}-\beta_{4}\right)$ have been described. All are hydrophilic, nonglycosylated, and located within the cell; only $\beta_{2}$ has been reproducibly shown to form cardiac L-VDCCs. The $\beta$ subunit does not have a membrane-spanning region. It is tightly bound to a highly conserved motif in the cytoplasmic linker between repeats I and II of all cloned high voltage-activated $\alpha_{1}$ subunit isoforms, called the $\alpha$-interaction domain (AID) (32, 33 ), and also to a secondary site (34). Just recently, elucidation of the high-resolution 3D structure (34-36) of a $\beta$ subunit has shed light on the molecular mechanism of binding of the $\alpha_{1}$ to $\beta$ subunits. Previous work suggested that the $\beta$ subunit interacts with $\alpha_{1}$ primarily through the $\beta$-interaction domain (BID), which binds directly to the AID. However, Van Petegem and colleagues (35) reported that the BID engages the AID through a conserved hydrophobic cleft, termed the $\alpha$-binding pocket (ABP). Interference with AID-ABP binding might provide a novel way to modulate $\mathrm{Ca}^{2+}$ channel function in pathological states. The I-II loop of the $\alpha_{1}$ subunit contains an endoplasmic reticulum retention signal that restricts cell surface expression. The $\beta$ subunit reverses the inhibition imposed by the retention signal (37). Recent structural modeling and X-ray crystallography revealed that the $\beta$ subunits share homology with the Src homology 3-guanylate kinase (SH3-GK) module of the membrane-associated guanylate kinase family of scaffolding proteins (38). Structural and biochemical characterization of this SH3-GK module of the $\beta$ subunit by McGee et al. (39) demonstrated that the functional $\beta$ subunit requires intramolecular and intermolecular interaction between the SH3 and GK domains. This hypothesis was elaborated by introducing mutations in the rat $\beta_{2 a}$ subunit. The interaction between the $\alpha_{1 \mathrm{~A}}$ and $\beta_{2 \mathrm{a}}$ subunit was disrupted and, as a consequence, the inactivation kinetics of the $\mathrm{Ca}^{2+}$ channel currents were altered. After coexpression of $\beta_{2 a}$ subunits with complementary mutations in their SH3 and GK domains, these deficits were functionally rescued through intermolecular $\beta$ subunit assembly. This model indicates that the BID includes elements from both the $\beta$-SH3 and $\beta$-GK domains.

The roles of the $\beta$ auxiliary subunits in influencing channel function Though much knowledge has been accumulated about the multiple roles of the $\beta$ subunit in the processing and functioning 
of the L-VDCC using heterologous recombinant coexpression of the different subunits $(23,40)$, the physiological significance of subunit interaction in the context of native tissue is only just beginning to be studied via transgenic approaches and adenovirus-mediated intracellular incorporation of genes encoding $\mathrm{Ca}^{2+}$ channel $\beta$ subunits into single cells $(5,41,42)$. In general, coexpression of $\beta$ subunits modulates the biophysical properties of the L-VDCC $\alpha_{1}$ subunit, producing a leftward shift of the current-voltage relationship, which is consistent with the involvement of the S4 region of the $\alpha_{1}$ subunit voltage-sensor region. However, the precise interpretation of the data is not straightforward due to the fact that oocytes and most mammalian cells express endogenous $\alpha_{1}, \alpha_{2} / \delta$, and $\beta$ subunits (40). Moreover, it has been shown that $\alpha_{1}$ subunits expressed in the absence of $\beta$ subunits are not regulated by the $\beta$-adrenergic system (43) or by $\mathrm{pH}$ changes (44). Frequency- and prepulse-dependent facilitation of L-VDCC activity is regulated by certain classes of $\beta$ subunits (45). By employing an antisense strategy to lower the numbers of endogenous $\beta$ subunits in oocytes, leaving only $\alpha_{1}$ subunits intact, a loss of current occurred, implying that the $\beta$ subunit functions in the assembly and expression of the $\alpha_{1}$ subunit (46). Our group provided evidence that the $\beta$ subunits have a chaperone-like role in trafficking $\alpha_{1 \mathrm{C}}$ subunits from the ER to the plasma membrane,and its insertion in the proper geometry (47). Recently, Kobrinsky et al. (48) identified, within the C terminal, a 153-aa sequence in the human cardiac short $\beta_{2 \mathrm{f}}$ and $\beta_{2 \mathrm{~g}}$ subunits that was essential for modulating $\mathrm{Ca}^{2+}$ channel function and interaction with the $\alpha_{1 \mathrm{C}}$ subunit. These 2 functional, short $\beta_{2}$ subunit splice variants lack the protein kinase A (PKA) phosphorylation site and the BID (32) as well as part of the $\beta$-SH3-GK domain and helix $\alpha_{3}$ of the $\alpha_{1}$ subunit-binding pocket. Viard et al. (49) demonstrated that a region of this $\beta_{2 a}$ subunit is involved in PI3K-induced increases of $\mathrm{Ca}_{\mathrm{v}} 1.2$ (rat brain) channel density. The PI3K-induced regulation is mediated by phosphatidylinositol 3,4,5-trisphosphate-activated protein kinase $\mathrm{B}$ (also called Akt) and requires phosphorylation of $\beta_{2 a}$ subunits on Ser574, which is common to all splice variants of the $\beta_{2}$ subunits. These results indicate that PI3K regulates VDCC trafficking to the plasma membrane and may be a general mechanism for the regulation of $\mathrm{Ca}^{2+}$ entry in excitable cells (49). The $\beta_{1}$ subunit has a crucial role in EC coupling, as proven in $\beta_{1}$-KO mice, which suffer from impaired EC coupling and early lethality (50). The exact mechanism for the lack of EC coupling is not known, but it is possible that the deficiency in the assembly process of the $\alpha_{1} / \beta_{1}$ complex results in the degradation of the $\alpha_{1}$ subunit. The role of the $\beta_{2}$ subunit in EC coupling is unclear (51). $\beta_{3}$-null mice have no detectable abnormalities in the heart (52).

Hullin et al. (53) cloned 2 distinct $\beta$ subunits, $\beta_{2}$ and $\beta_{3}$, from rabbit heart and showed an association with the $\alpha_{1}$ subunit of the L-VDCC. The aa homology of these subunits was similar to that of $\beta_{1}$, originally cloned from skeletal muscle (12). Subtypes of the $\beta$ subunits are revealed frequently, e.g., the 2 splicing products, $\beta_{2 \mathrm{a}}$ and $\beta_{2 \mathrm{~b}}$, which have been shown to lend more diversity to channel function. It should be noted that $\beta_{2 a}$, an important subtype of this subunit, is palmitoylated $(54,55)$. This modification is associated with membrane targeting of nontransmembrane proteins (such as the $\beta$ subunit) to specific areas including the plasma membrane. Another subtype, the $\beta_{2 c}$, has been cloned from rabbit brain (53). The role of the $\beta$ subunits in L-VDCC expression is well characterized although we still do not know how the $\beta$ subunits modulate preexisting $\alpha_{1}$ subunit expression. Colecraft et al. (56) devised a novel system in which recombinant adenoviruses were used to express GFP-fused $\beta_{1-4}$ subunits in cultured adult rat cardiomyocytes. While all 4 subunits $\left(\beta_{1 b}, \beta_{2 a}\right.$, $\left.\beta_{3}, \beta_{4}\right)$ increased L-VDCC density, their effects on inactivation kinetics were nonuniform. The conclusion of this study was that overexpression of the newly cloned rat splice variant of a $\beta_{2 b}$ subunit in adult rat heart cells yielded channels that were identical to those in the native unmodified rat heart cells. The authors stated that this work provided an "experimental paradigm to explore novel function of ion channel subunits in their native environments." While this system is superior to heterologous systems, it does not provide the whole animal model necessary to explore beyond a single cell.

$\beta_{3}$ is most abundant in brain but is also expressed in heart, aorta, trachea, lung, and skeletal muscle. In 2 studies $(57,58), \beta_{3}$-KO models were engineered. In 1 study, (58) a high-salt diet led to hypertension, smooth muscle hypertrophy, cardiac hypertrophy, reduced channel in aortic cells, slowed inactivation rate, and a decreased DHP-sensitivity. In the other study (57), $\beta_{3}-\mathrm{KO}$ mice showed altered pain processing due to a decrease in the expression of $\mathrm{N}$-type $\mathrm{Ca}^{2+}$ channels via functional alterations of $\mathrm{Ca}^{2+}$ currents in neurons projecting to the spinal cord. Expression levels of various $\beta$ subunit isoforms $(53,56,59)$ indicate that altered singlechannel behavior in human heart may be due to differential effects and changes in $\beta$ subunit gene products.

A valuable approach to characterizing $\beta$ subunits in normal and diseased tissues is to compare normal and abnormal tissues from human heart with a mouse model of a similar disease. Although $\beta$ subunits appear rate limiting for L-VDCC expression $(56,60)$, our group found that $I_{\mathrm{Ca}}$ density in cardiomyocytes from $\mathrm{Tg}$ mice overexpressing the $\alpha_{1 \mathrm{C}}$ subunit of L-VDCC increased by $30-40 \%$ in comparison with WT mice without significant change in $I_{\mathrm{Ca}}$ activation and inactivation kinetics prior to the development of heart failure. However, Western blots revealed a 2.7 -fold increase in $\mathrm{Ca}_{\mathrm{v}} 1.2$ protein expression $(61,62)$. This discrepancy was resolved when it was shown that single-channel gating was impaired in cardiomyocytes of 4 -month old $\alpha_{1 \mathrm{C}}-\mathrm{Tg}$ mice. Immunoblot analysis also showed that auxiliary subunits $\beta_{2}$ and $\alpha_{2} / \delta$ play important modulator roles, and their expression was decreased. Interestingly, in the older age groups of $\mathrm{Tg}$ mice with the heart failure phenotype, the $\beta_{2}$ subunit expression pattern is reversed, and we observed a 2 -fold increase of protein expression levels (A. Schwartz, unpublished data) compared with that of WT littermates. These data lend credence to the concept that in human heart failure, alterations of auxiliary subunits play a vital role in changing the kinetics of the L-VDCC pore unit (61). We hypothesize that some types of heart failure are possibly L-VDCC $\beta$ subunit channelopathies.

\section{Role of calmodulin as a signaling molecule in $\mathrm{Ca}^{2+}$ dependent inactivation and EC coupling}

The cardiac L-VDCC displays long-lasting openings and minor voltage-dependent inactivation (VDI) components. In the heart, $\mathrm{Ca}^{2+}$-dependent inactivation (CDI) is compatible with the length of the $\mathrm{Ca}^{2+}$-mediated plateau phase in the AP. Therefore, $\mathrm{Ca}^{2+}$ induced inhibition of the cardiac VDCC plays a critical role in controlling $\mathrm{Ca}^{2+}$ entry and downstream signal transduction as well as ensuring that contraction and relaxation cycles of the heart muscle fiber are coordinated. 
A Closed channel rest

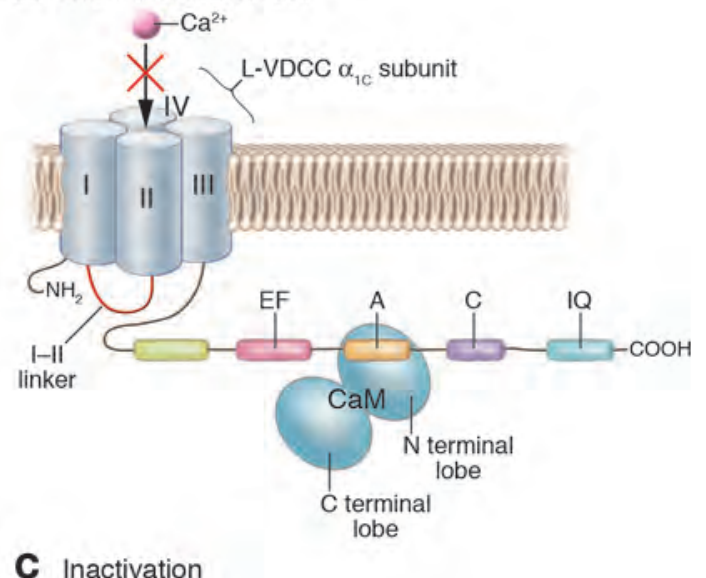

Inactivation
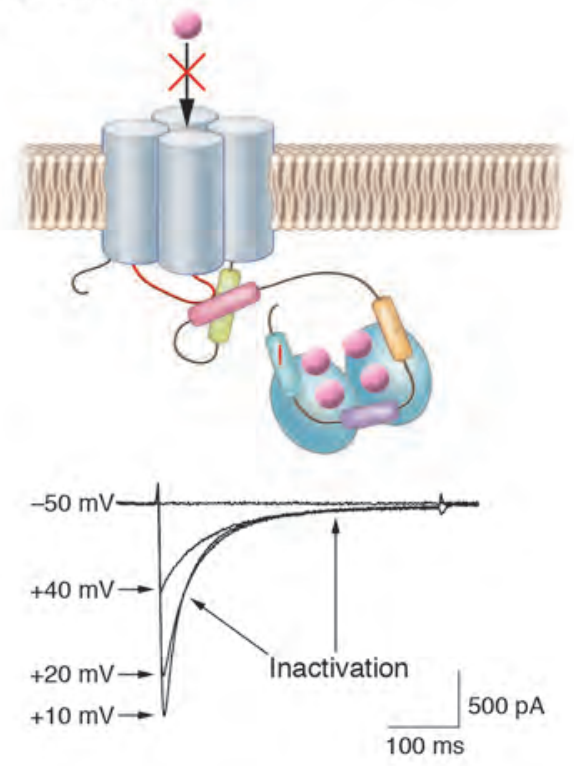

B Open-channel activation

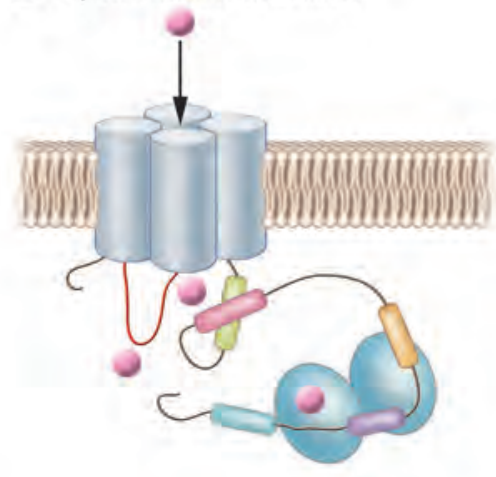

D Facilitation

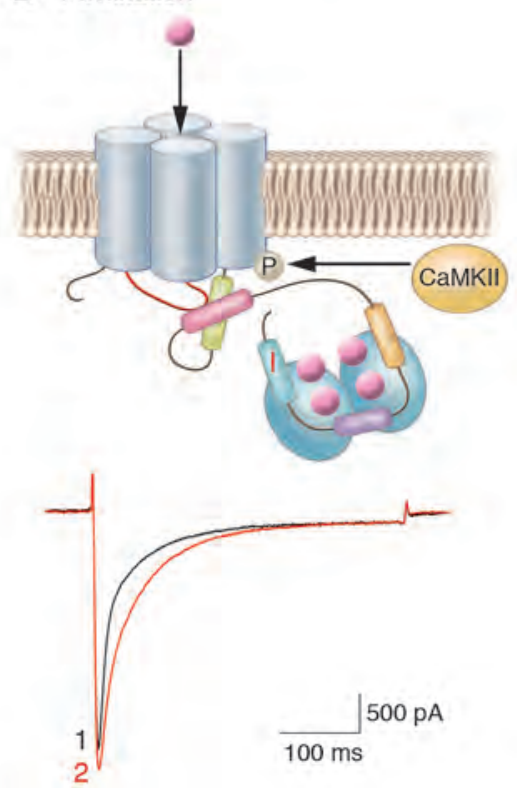

Figure 3

Model for CDI and VDI. (A) $\mathrm{Ca}^{2+}$ channel at rest when no $\mathrm{Ca}^{2+}$ influx occurs. At rest, in the absence of $\mathrm{Ca}^{2+}$, the CaM binds to peptide $\mathrm{A}$, located between the EF hand and the IQ motif of the $C$ terminus of the L-VDCC $\alpha_{1 C}$ subunit. In response to a depolarizing stimulus, Ca ${ }^{2+}$ enters through the L-VDCC and binds to CaM. In the open $\mathrm{Ca}^{2+}$ channel state, the EF hand prevents structural conformation of the I-II loop required to block $\mathrm{Ca}^{2+}$ entry through the channel pore (B). In addition, the hydrophobic I1654 in the IQ motif is a stabilizing factor preventing the occlusion of the pore. Upon elevation of $\left[\mathrm{Ca}^{2+}\right]_{\mathrm{i}}$ (depolarization), the $\mathrm{Ca}^{2+} / \mathrm{CaM}$ complex undergoes the Ca ${ }^{2+}$-dependent conformational change that relieves the inhibition of EF hand, permitting the I-II loop to interact with the pore and accelerate the fast inactivation process $(\mathbf{C})$. The graph shows representative $I_{\mathrm{Ca}}$ traces evoked by depolarization from $-50 \mathrm{mV}$ to $+40 \mathrm{mV}$, as labeled, using $-60 \mathrm{mV}$ as holding potential. (D) Involvement of CaM and CaMKII in the facilitation process. CaMKII enhances the $I_{\mathrm{Ca}}$ through phosphorylation of L-VDCC. We show murine whole-cell $I_{\mathrm{Ca}}$ generated from paired depolarizing pulses $(-60 \mathrm{mV} \pm 10 \mathrm{mV}$ at $0.5 \mathrm{~Hz})$ representing $\mathrm{Ca}^{2+}$-dependent facilitation (graph).

Several lines of evidence suggest that the $\mathrm{Ca}^{2+}$-binding protein calmodulin (CaM) is a critical sensor in mediating the inactivation process. In the $C$ terminal tail of the pore-forming $\alpha_{1 C}$ subunit of the L-VDCC, there is a $\mathrm{Ca}^{2+}$-dependent CaM-binding isoleucine-glutamine (IQ) motif that has been implicated in autoregulation (Figure 2). Substitution of isoleucine (I1624) by alanine (Ala) prevents $\alpha_{1 \mathrm{C}}$ binding to CaM and as a consequence eliminates CDI, promoting $\mathrm{Ca}^{2+}$-dependent facilitation (63-65), which contributes to a force-frequency relationship of heart. Originally, an EF hand was identified as a crucial determinant of CDI. Peterson et al. (66) suggested that a 4-aa cluster (VVTL) within the EF-hand region was involved in the CDI process; however, subsequent studies could not confirm this finding. Pitt et al. (67), using $\mathrm{Ca}^{2+}$-insensitive CaM mutants (with all $4 \mathrm{Ca}^{2+}$ binding sites destroyed), found that the $\alpha_{1 \mathrm{C}}$ subunit contains an apoCaM site requiring $10-100 \mathrm{nM} \mathrm{Ca}^{2+}$ for tethering. Two other sequences (labeled peptides A and C) between the EF hand and the IQ motif are also implicated in CaM binding. Upon depolarization and concomitant $\mathrm{Ca}^{2+}$ influx, $\left[\mathrm{Ca}^{2+}\right]_{i}$ elevates to a $\mu \mathrm{M}$ level causing $\mathrm{Ca}^{2+}$ binding to the prebound $\mathrm{CaM}$, which 
then rapidly engages the IQ motif and promotes inactivation. Recently, Kim et al. (68) identified I1654 in the CaM-binding IQ motif as a link between the $\mathrm{Ca}^{2+}$ sensor and the downstream inactivation machinery. The study suggested a unified model for CDI and VDI of L-VDCC utilizing the I-II linker of the channel as a blocking particle (Figure 3). However, the molecular details of the interaction between the CaM and the $\mathrm{C}$ terminal of the $\alpha_{1 \mathrm{C}}$ need to be further elucidated. Kobrinsky et al. reported (48) that the $\alpha_{1 \mathrm{C}}$ subunit $\mathrm{N}$ terminal tail may have a role in channel trafficking and is a target for $\beta$ subunit modulation. The authors proposed hypothetical molecular arrangements of the $\beta$ subunit modulation of the $\mathrm{Ca}_{\mathrm{v}} 1.2$ channel, implying that the $\beta$ subunit acts as a "molecular wedge" that prevents the $\mathrm{N}$ terminus of the $\alpha_{1 C}$ subunit from blocking the pore. The data, generated from coexpression studies in African green monkey kidney cells (COSs), provided evidence that the CDI is not mediated solely by determinants of the $\alpha_{1 C}$ subunit $C$ terminal tail.

$\mathrm{CaM}$ is also involved in EC coupling. Yang and coworkers (69) demonstrated that adenoviral expression of a mutant CaM lacking all $4 \mathrm{Ca}^{2+}$-binding sites (CaM 1-4) surprisingly markedly enhanced the amplitude of $\left[\mathrm{Ca}^{2+}\right]_{i}$ transients in cultured rat ventricular myocytes. The underlying mechanism involves the augmentation of $I_{\mathrm{Ca}}$ density with slowed inactivation time associated with an elevation of the $\mathrm{Ca}^{2+} / \mathrm{CaM}$-dependent protein kinase II (CaMKII). One of the appealing working hypotheses explaining the CaM 1-4 positive inotropic effect is that the excessive CaM 1-4 displaces apoCaM from the L-VDCC $\alpha_{1 C}$ subunit $\mathrm{C}$ terminal tail, resulting in an increase in apoCaM concentration in the cytosol. Despite the increase in apoCaM concentration, the total CaM concentration remains unchanged. This process prevents CaM activation at the $\mathrm{C}$ terminus of $\alpha_{1 \mathrm{C}}$, which would concomitantly increase the $\mathrm{Ca}^{2+} / \mathrm{CaM}$ available to activate CaMKII. $\mathrm{Ca}^{2+} / \mathrm{CaM}$ activates CaMKII, which increases L-VDCC by inducing a gating mode characterized by long channel openings (70). CaM-CaMKII-L-VDCC crosstalk has a central role in contractility and $\mathrm{Ca}^{2+}$ homeostasis. In addition, substantial evidence supports its involvement in cardiac hypertrophy and failure (71). A growing body of evidence suggests that CaMKII is a proarrhythmic signaling molecule (72). Results by Tessier and colleagues (73) indicated that $\mathrm{Ca}^{2+}$-dependent regulation of $I_{\text {to }}$ (transient outward $\mathrm{K}^{+}$current, encoded by $\mathrm{K}_{\mathrm{v}} 1.4$ ) is achieved mainly via CaMKII activation in human atrial myocytes. Since CaMKII is upregulated during atrial fibrillation (AF), there is evidence that changes in $\left[\mathrm{Ca}^{2+}\right]_{i}$ homeostasis may initiate electrical remodeling during AF. CaMKII structure and function data and other recent evidence together suggest that CaMKII inhibition may serve as a potential strategy for treating myocardial dysfunction and arrhythmias in the setting of structural heart disease $(71,74)$. An important signaling molecule involved in the complex pathway regulating $\mathrm{Ca}^{2+}$ homeostasis is the nuclear factor cAMP-responsive element-binding protein (CREB) (75), which is a major downstream target for CaMKII. CREB normally regulates the transcription of target genes that encode contractile proteins, proteins involved in generating energy, and proteins required for cardiac myocyte growth and viability. A variety of intracellular signaling molecules may be involved in CREB phosphorylation and activation, including PKA and CaMKII in response to elevations in $\left[\mathrm{Ca}^{2+}\right]_{i}$. Studies suggest that therapies designed to increase CREB activity in the failing heart might slow the progression of heart failure.

\section{$\mathrm{Ca}^{2+}$ channel antagonists and $\mathrm{Ca}^{2+-b i n d i n g ~ d o m a i n s ~}$}

The L-VDCC is an important pharmacologic target in the treatment of a number of conditions. In the late 1960s, Fleckenstein showed that $\mathrm{Ca}^{2+}$-antagonists, such as verapamil, protected the rat heart against structural damage associated with prolonged $\left[\mathrm{Ca}^{2+}\right]_{\mathrm{i}}$ overload. Among the many problems that arise from $\mathrm{Ca}^{2+}$ overload, ventricular ectopic rhythm, e.g., ventricular fibrillation (VF), is the most prominent and can be life threatening. In pharmacological models, $\mathrm{Ca}^{2+}$ channel blockers (CCBs) are considered promising drugs to treat supraventricular arrhythmias, hopefully preventing lethal VF. We emphasize, however, that the effects of these drugs have not emerged as unequivocally favorable in all clinical studies to date. Verapamil and diltiazem can, in some cases, prevent episodes of acute ischemic VF in humans, but they do not have as much of a beneficial effect on overall mortality as the $\beta$-blockers and the angiotensin-converting enzyme (ACE) inhibitors. The clinical implications of this finding, reported in different clinical trials, are similar to those reported for encaidine and flecainidine, class IC antiarrhythmics, in the Cardiac Arrhythmia Suppression Trial (76). Patients suffering from coronary disease may die of either heart failure or arrhythmias. Likewise, arrhythmias ascribable to disorders of conduction are also treated with CCBs that function, presumably, by inhibiting conduction disturbances in the sinoatrial or atrioventricular nodes. Although CCBs bind specifically to regions of the $\alpha_{1 C}$ subunit of the L-VDCC, these drugs are not currently judged as being helpful in the setting of congestive heart failure. In fact, all clinical trials to date, with the exception of the Prospective Randomized Amlodipine Survival Evaluation (PRAISE I) study on congestive heart failure patients, were failures. However, a subgroup analysis (PRAISE II) revealed that improved clinical symptoms were seen only in patients with heart failure of a nonischemic cardiomyopathic nature. A favorable effect on survival was found only in patients without a history of angina (77). In the Third Vasodilator-Heart Failure Trial (78) (V-HeFT III), felodipine was administered to patients with congestive heart failure in a setting of stable therapy with enalapril, diuretics, and digoxin. The drug had neither a beneficial nor deteriorating effect despite the improvement in exercise performance and LV function, as reported previously in the $\mathrm{V}$-HeFT II trial in patients with chronic heart failure (79). Chronic nifedipine (which has strong peripheral vasodilating effects) therapy caused a higher incidence of clinical deterioration and worsening of heart failure $(80,81)$. The DEFIANT-I study (Doppler Flow and Echocardiography in Functional Cardiac Insufficiency: Assessment of Nisoldipine Therapy) was a double-blind randomized study of the effects of the DHP nisoldipine on LV size and function after acute myocardial infarction. Diastolic LV function improved in patients recovering from acute myocardial infarction (82). The Danish Verapamil Infarction Trial II (DAVIT II) demonstrated that long-term treatment with verapamil significantly improved reinfarction survival after acute mycocardial infarction. Verapamil significantly reduced (35\%) the 18month mortality rate but produced no change in mortality in the heart failure group (83). Hypertensive patients are often treated with CCBs to reduce cardiovascular disease risk, but the overall benefit compared with atenolol and hydrochlorothiazide and ACE inhibitors is both controversial and problematic. The Controlled Onset Verapamil Investigation of Cardiovascular End Points (CONVINCE) trial indicated that the effectiveness 
of CCB therapy was comparable to diuretic and $\beta$-blocker treatment in reducing cardiovascular disease (84). According to the Multicenter Diltiazem Postinfarction Trial (85) analysis, diltiazem exerted no overall effect on mortality or cardiac events in a large population of patients with previous infarction, but in patients with pulmonary congestion, diltiazem was associated with an increased number of cardiac events and mortality. Interestingly, the increase in mortality was not accompanied by a worsening of heart failure. Despite these concerns, in the Studies of Left Ventricular Dysfunction Trial (SOLVD), 3-35\% of the patients were treated with CCBs in addition to digitalis and diuretics. Concomitant CCB use was associated with significantly increased risks of fatal and nonfatal myocardial infarction (86). CCBs have a favorable systemic vasodilator effect and should improve diastolic relaxation. Besides that, one would assume that CCBs, in inhibiting $\mathrm{Ca}^{2+}$ influx into myocardial cells, might be beneficial because theoretically they could reduce $\mathrm{Ca}^{2+}$ overload, an important trigger for activating certain downstream $\mathrm{Ca}^{2+}$-dependent pathways involved in hypertrophy and cardiac dysfunction. Clinical trials to date, however, have been disappointing. In fact, it has been suggested that the effects of CCBs on mortality in patients with heart failure may be associated with increased sympathetic activity. Summing up the therapy of heart failure, the $\beta$-adrenergic receptor ( $\beta$-AR) blockers, ACE inhibitors, diuretics, and aldosterone receptor(s) inhibitors (spironolactone and new derivatives) have achieved therapeutic success probably through multiple actions that culminate in a positive "remodeling" of the diseased heart (reviewed in ref. 87). The state of the art in the pharmacotherapy of heart failure, considering its epidemic nature in the world, is disappointing. Recent reviews have emphasized that we are dealing with a highly complex, multifaceted disease, almost as complex as the malignant transformation process.

Several laboratories using a variety of techniques have identified individual amino acids within the L-VDCC $\alpha_{1}$ subunit that participate in the formation of the major drug-binding domains. The 3 classes of organic CCBs include DHPs, phenylalkylamines (PAAs), and benzothiazepines (BTZs). Each drug type, DHP, PAA, and BTZ, has separate, but overlapping or allosterically linked, $\mathrm{Ca}^{2+}$ channel-binding sites at IIIS6 and IVS6, IVS6 and IIIS6, and IVS6 motifs (Figure 2), respectively. Nine amino acid residues in segments IIIS5 (88), IIIS6 (89), and IVS6 contribute to the DHP pocket. The 4-aa region (YMAI) in motif IVS6 is a common binding site for both BTZ (90) and PAA $(91,92)$.

As discussed above, although CCBs bind specifically to regions of the $\alpha_{1 C}$ subunit of the L-VDCC, these drugs are not currently judged as being helpful in the setting of congestive heart failure and should be used with caution, if at all. All clinical trials underscore the use of drugs that inhibit the sympathetic nervous system and reduce the load on the heart.

\section{Use dependence}

Less detailed structural information is known regarding the mechanism of use-dependent block, a feature that is critical to the activity of therapeutically successful L-VDCC antagonists. Starmer et al. (93) proposed the "guarded receptor hypothesis" in the setting of the $\mathrm{Na}^{+}$channel to explain the mechanism of use-dependent block by the $\mathrm{Na}^{+}$channel blocker antiarrhythmic drugs although this model may be applicable for the $\mathrm{Ca}^{2+}$ channels in cardiac muscle as well. A use-dependent pattern is described where peak $I_{\mathrm{Ca}}$ is progressively reduced by a train of depolarizing test pulses. Verapamil and diltiazem preferentially interact with the open and inactivated states of the channel (reviewed in ref. 94). The more frequently the $\mathrm{Ca}^{2+}$ channel opens, the better is the penetration of the drug to the binding site. This explains their preferential effect on nodal tissue in paroxysmal supraventricular tachycardia. The lack of use dependence and the presence of voltage sensitivity of the DHPs in regard to their binding explains their vascular selectivity. Hering et al. (95) were among the first to establish a relationship between $\mathrm{Ca}^{2+}$ channel inactivation and use-dependent $\mathrm{Ca}^{2+}$ channel block by PAA. Since that time, single amino acids have been identified as inactivation determinants in motifs IIIS6, IVS6, and IVS5, with some of them also serving as high-affinity determinants for the DHP receptor site (94-96).

\section{The L-VDCC in heart failure}

There is overwhelming evidence that EC coupling in the heart depends on the function of the L-VDCC. Although considerable information is known regarding the role of the L-VDCC in EC coupling, the consequence of increased $\mathrm{Ca}^{2+}$-channel density in hypertrophy and cardiac failure remains speculative. In fact, most investigators report no change in the L-VDCC or downregulation in end-stage heart failure. Nevertheless, almost everyone agrees that alteration of intracellular $\mathrm{Ca}^{2+}$ handling in the myocardium is relevant to both human and animal models of heart disease (as reviewed by Benitah et al. in ref. 97). Haase and coworkers (98) investigated the effect of $\alpha_{1}$ and $\beta$ subunits in cardiac preparations from normal and hypertrophied human hearts. They found a significant increase in the number of DHP receptors expressed in hypertrophied hearts compared with normal hearts. Hullin et al. (99) examined the role of L-VDCC subunits expressed in allografts from hearts with diastolic heart failure. The transcript and protein expression levels of the $\beta$ subunit were decreased while the expression levels of other subunits were unchanged; however, the interpretation of the results from transplanted hearts may be more complex. On the functional level, Schroderet al. (100) used single-channel analyses to demonstrate that single-channel current activity was markedly enhanced in the failing heart compared with nonfailing control hearts as a result of increased open probability and availability. However, extrapolating these findings to whole-cell current is difficult. Although an increased $I_{\text {Ca }}$ would be predicted from these single-channel data, no increase was found when $I_{\mathrm{Ca}}$ was measured in whole-cell preparations. Such a discrepancy might be explained if the cardiomyocytes from these failing hearts expressed fewer L-VDCCs than normal although the authors reported no significant changes in either $\alpha_{1 \mathrm{C}}$ subunit transcript or protein expression levels. Schroder et al. (100) proposed 2 alternative explanations: (a) the increased channel activity reflects an increase in PKA-dependent phosphorylation of the $\alpha_{1 C}$ (due to altered dephosphorylation) in the failing heart; and (b) auxiliary channel subunits expressed in the cardiomyocytes modulate $I_{\text {Ca }}$.

\section{L-VDCC in AF}

The L-VDCCs also play a key role in experimental and clinical AF. During the very early phase of electrical remodeling in a rabbit model of rapid atrial pacing (101), reduction in $\beta_{2}$ subunit expression paralleled a reduction in $I_{\mathrm{Ca}}$ prior to changes in the 
$\alpha_{1 C}$ subunit mRNA levels. These data support the concept that reduced expression of $\beta$ subunits is responsible for the reduction of functional L-VDCC.

In contrast with the rabbit model, the expression of the L-VDCC $\alpha_{1 C}$ and $\alpha_{2}$ subunits was not decreased in atrial myocardium of patients with chronic AF, suggesting no change in $I_{\mathrm{Ca}}$ density (102). These results are in conflict with other published results demonstrating a decrease in $I_{\mathrm{Ca}}$ density $(103-105)$ and protein content of the $\alpha_{1 C}$ subunit of L-VDCC in clinical AF $(106,107)$. However, we have to remember that whole cell $I_{\mathrm{Ca}}$ is determined by the equation $I_{\mathrm{Ca}}=N \times i \times p_{0} \times f_{\text {active }}$, where $N$ is the number of functional channels in the cell, $i$ is the single channel current amplitude, $f_{\text {active }}$ is the fraction of available channels, and $p_{0}$ is the open probability of the available channels to be in the open state. Therefore, the reduction of $I_{\mathrm{Ca}}$ could be the result of a change in single-channel gating characteristics. Indeed, Klein et al. (107) revealed an increased channel open probability associated with reduced protein expression of the $\alpha_{1 C}$ subunit. Christ et al. (105), on the contrary, suggest that an increase in protein phosphatase $2 \mathrm{~A}$ activity contributes to the impaired $I_{\mathrm{Ca}}$ density in AF, which may imply reduced single-channel activity. Overall, based on the results available to date, it appears there are other regulatory pathways and factors impacting the L-VDCC during AF and heart failure (108-110). It is of considerable interest that, after the many years since the cloning of the L-VDCC, a mutation has finally been demonstrated in the $\alpha_{1 C}$ subunit (111). The related disease, now called Timothy Syndrome, is characterized by syncope and sudden death from cardiac arrhythmias and is attributed to a G406R as well as a G402S mutation, occurring in exon 8.

\section{EC coupling gain}

$\mathrm{Ca}^{2+}$ entry via L-VDCCs is the major trigger for $\mathrm{SR} \mathrm{Ca}^{2+}$ release $\left(\mathrm{Ca}^{2+}\right.$ sparks) by RyR2, and summation of the $\mathrm{Ca}^{2+}$ sparks during depolarization of the cell underlie the basis for $\left[\mathrm{Ca}^{2+}\right]_{\mathrm{i}}$ homeostasis. Single cardiomyocytes from failing rat heart displayed smaller $\left[\mathrm{Ca}^{2+}\right]_{\mathrm{i}}$ transients and compromised contractility despite the unchanged $I_{\mathrm{Ca}}(112)$. The same findings were demonstrated in failing human cardiomyocytes (113). The temporal characteristics of the voltage clamp-induced $\mathrm{Ca}^{2+}$ sparks did not change. The following could be accountable for the reduction in $\left[\mathrm{Ca}^{2+}\right]_{\mathrm{i}}$ transient: (a) decrease in $I_{\mathrm{C}}$; (b) reduction in the sensitivity of RyR2 to the $\mathrm{Ca}^{2+}$ trigger; (c) reduction in $\mathrm{SR} \mathrm{Ca}^{2+}$ load, characteristic of defective EC coupling; and (d) a change in the properties of the $\mathrm{SR} \mathrm{Ca}^{2+}$ release events. We believe that defective EC coupling is a feasible explanation for the observed phenomenon. The relationship between $I_{\mathrm{Ca}}$ and the probability of triggering $\mathrm{Ca}^{2+}$ release from the SR has been termed EC coupling gain $(114,115)$. The authors $(112)$ indicated that EC coupling gain was decreased in their heart failure rat model. The sparks $\left(\mathrm{P}_{\mathrm{s}}\right)$ and $I_{\mathrm{Ca}}$ or $\left[\mathrm{Ca}^{2+}\right]_{i}$ are integrated over a fixed time period $(t)$. The ratio of these time integrals $\int \mathrm{P}_{\mathrm{s}} d t / \int I_{\mathrm{Ca}} d t$ or $\int\left[\mathrm{Ca}^{2+}\right]_{\mathrm{i}} d t / \int I_{\mathrm{Ca}} d t=f$, where $f$ is a measure of the ability of $I_{\mathrm{Ca}}$ to trigger SR $\mathrm{Ca}^{2+}$ release. The decreased EC gain appears to be a sign of a defect in the coupling between the L-VDCC and RyR2s. In many cases, the reduced gain is due to a reduced $\mathrm{SR} \mathrm{Ca}^{2+}$ load observed in some types of heart failure $(116,117)$.

Lindner et al. (118) investigated $\mathrm{Ca}^{2+}$ sparks in cardiomyocytes from terminally failing human hearts and demonstrated significant differences in specific spontaneously arising $\mathrm{Ca}^{2+}$ spark properties compared with nonfailing hearts (decreased spark frequency and increased time to peak and half-time decay). The authors suggest that besides the decreased SR $\mathrm{Ca}^{2+}$ load (119), other mechanisms in the $\mathrm{Ca}^{2+}$ release mechanism should be considered (120). In contrast to the results of Gomez et al. (112), Shorofsky et al. (121), using cardiomyocytes from hypertrophied spontaneously hypertensive rats, found an increase in contractility, $\left[\mathrm{Ca}^{2+}\right]_{\mathrm{i}}$ transients, and the average $\mathrm{Ca}^{2+}$ spark amplitude (big sparks) without any alteration in $I_{\mathrm{Ca}}$ or $\mathrm{SR} \mathrm{Ca}^{2+}$ load. These results suggest an increase in EC coupling gain (115), which means that the coupling between $\mathrm{Ca}^{2+}$ entry through L-VDCC and $\mathrm{Ca}^{2+}$ release from the SR would be enhanced although this could not account entirely for the big $\mathrm{Ca}^{2+}$ sparks. Several other possibilities include altered transverse-tubule structure and increased phosphorylation of RyR2 and L-VDCC (122).

Reduced EC coupling gain may explain how Tg animals develop heart failure. For example, Tg overexpression of NCX1 (123) resulted in a phenotype with severe hypertrophy associated with a reduction of EC coupling gain as a consequence of the increased $I_{\mathrm{Ca}}$ and decreased $\left[\mathrm{Ca}^{2+}\right]_{\mathrm{i}}$ transient. According to the authors' interpretation, the overexpressed NCX behaves like a sponge and helps reduce the amount of $\mathrm{Ca}^{2+}$ entering through the L-VDCC before the trigger-induced $\mathrm{Ca}^{2+}$ release from SR. In contrast, Henderson et al. (124) reported a cardiac-specific NCX KO mouse model with normal cardiac function. The cardiac phenotype included decreased $I_{\mathrm{Ca}}$ associated with normal $\left[\mathrm{Ca}^{2+}\right]_{i}$ transients amplitude. The authors hypothesized that the interaction between trigger $\mathrm{Ca}^{2+}$ and RyR2 is more efficient in the KO mice than in WT mice (EC coupling gain increase). Interestingly, at the onset of cardiac hypertrophy in the $\alpha_{1 \mathrm{C}} \mathrm{Tg}$ model, the gain function of EC coupling was uncompromised, and $\mathrm{SR} \mathrm{Ca}^{2+}$ content, and unitary properties of $\mathrm{Ca}^{2+}$ sparks were unchanged (62).

It is common knowledge that heart failure is characterized by a disruption in the cardiac $\beta$-AR system. Data by Grandy et al. (125), for example, provide evidence that cardiac-specific overexpression of $\beta_{2}$-AR increases EC coupling gain. Interestingly, $I_{\mathrm{Ca}}$ is decreased and accompanies the increased SR $\mathrm{Ca}^{2+}$ load and the frequency and amplitude of spontaneous $\mathrm{Ca}^{2+}$ sparks. It has been assumed that augmentation of $\beta$-AR signaling has therapeutic potential, and these observations suggest that increased EC coupling gain is the underlying mechanism.

Clearly, the link between reduced EC coupling gain and heart failure is important; however, more investigation is required to improve our understanding of the defects in EC coupling in pathological cases.

We have endeavored here to provide an insight into the importance of $\mathrm{Ca}^{2+}$ in the life of the cardiac myocyte with a special emphasis on L-VDCCs, viewing molecular data through the filter of fundamental physiology. It is our belief that molecular-based cardiac physiology is at the doorstep of a major breakthrough, at which time a more complete understanding of the biochemical and biophysical processes will drive successful therapeutic interventions and treatment of heart disease.

\section{Acknowledgments}

We sincerely thank Geraldine Fuller-Bicer for assisting us with discussion and providing constructive criticism. The original studies referred to were supported by P01 HL 22619 
(A. Schwartz). We apologize to all authors whose work is not cited due to space limitations.

G. Mikala's present address is: Department of Hematology and Stem Cell Transplantation, National Medical Center, Budapest, Hungary.

S. Akhter's present address is: Division of Cardiothoracic Surgery, Department of Surgery, and Institute of Molecular Pharmacology and Biophysics, University of Cincinnati College of Medicine, Cincinnati, Ohio, USA.

Address correspondence to: A. Schwartz, Institute of Molecular Pharmacology and Biophysics, University of Cincinnati College of Medicine, Department of Surgery, 231 Albert Sabine Way, Cincinnati, Ohio 45267, USA. Phone: (513) 558-2400; Fax: (513) 558-1778; E-mail: schwara@email.uc.edu.
1. Ringer, S. 1883. A further contribution regarding the influence of the different constituents of the blood on the contraction of the heart. J. Physiol. 4:29-47.

2. Carafoli, E., Santella, L., Branca, D., and Brini, M. 2001. Generation, control, and processing of cellular calcium signals. Crit. Rev. Biochem. Mol. Biol. 36:107-260.

3. Ellis, S.B., et al. 1988. Sequence and expression of mRNAs encoding the alpha 1 and alpha 2 subunits of a DHP-sensitive calcium channel. Science. 241:1661-1664.

4. Mori, Y., et al. 1996. Molecular pharmacology of voltage-dependent calcium channels. Jpn. J. Pharmacol. 72:83-109.

5. Catterall, W.A. 2000. Structure and regulation of voltage-gated Ca2+ channels. Annu. Rev. Cell Dev. Biol. 16:521-555.

6. Finkbeiner, S., and Greenberg, M.E. 1998. Ca2+ channel-regulated neuronal gene expression. J. Neurobiol. 37:171-189.

7. Rottbauer, W., et al. 2001. Growth and function of the embryonic heart depend upon the cardiac-specific L-type calcium channel alpha1 subunit. Dev. Cell. 1:265-275.

8. Qin, N., Platano, D., Olcese, R., Stefani, E., and Birnbaumer, L. 1997. Direct interaction of gbetagamma with a C-terminal gbetagamma-binding domain of the $\mathrm{Ca} 2+$ channel alpha1 subunit is responsible for channel inhibition by $\mathrm{G}$ protein-coupled receptors. Proc. Natl. Acad. Sci. U. S. A. 94:8866-8871.

9. Yokoyama, C.T., et al. 2005. Mechanism of SNARE protein binding and regulation of Cav2 channels by phosphorylation of the synaptic protein interaction site. Mol. Cell. Neurosci. 28:1-17.

10. Perez-Reyes, E. 2003. Molecular physiology of lowvoltage-activated t-type calcium channels. Physiol. Rev. 83:117-161.

11. Lee, J.H., Cribbs, L.L., and Perez-Reyes, E. 1999. Cloning of a novel four repeat protein related to voltage-gated sodium and calcium channels. FEBS Lett. 445:231-236.

12. Takahashi, M., and Catterall, W.A. 1987. Dihydropyridine-sensitive calcium channels in cardiac and skeletal muscle membranes: studies with antibodies against the alpha subunits. Biochemistry. 26:5518-5526.

13. Cataldi, M., Perez-Reyes, E., and Tsien, R.W. 2002. Differences in apparent pore sizes of low and high voltage-activated Ca2+ channels. J. Biol. Chem. 277:45969-45976.

14. Klockner, U., Mikala, G., Schwartz, A., and Varadi, G. 1996. Molecular studies of the asymmetric pore structure of the human cardiac voltage-dependent Ca2+ channel. Conserved residue, Glu-1086, regulates proton-dependent ion permeation. J. Biol. Chem. 271:22293-22296.

15. Mikala, G., Bahinski, A., Yatani, A., Tang, S., and Schwartz, A. 1993. Differential contribution by conserved glutamate residues to an ion-selectivity site in the L-type Ca2+ channel pore. FEBS Lett. 335:265-269.

16. Koch, S.E., Bodi, I., Schwartz, A., and Varadi, G, 2000. Architecture of $\mathrm{Ca}(2+)$ channel pore-lining segments revealed by covalent modification of substituted cysteines. J. Biol. Chem. 275:34493-34500.

17. Bezanilla, F. 2002. Voltage sensor movements.
J. Gen. Physiol. 120:465-473.

18. Jiang, Y., Ruta, V., Chen, J., Lee, A., and MacKinnon, R. 2003. The principle of gating charge movement in a voltage-dependent $\mathrm{K}+$ channel. Nature. 423:42-48.

19. Starace, D.M., and Bezanilla, F. 2004. A proton pore in a potassium channel voltage sensor reveals a focused electric field. Nature. 427:548-553.

20. De Jongh, K.S., Warner, C., and Catterall, W.A. 1990. Subunits of purified calcium channels. Alpha 2 and delta are encoded by the same gene. J. Biol. Chem. 265:14738-14741.

21. Qin, N., Yagel, S., Momplaisir, M.L., Codd, E.E., and D'Andrea, M.R. 2002. Molecular cloning and characterization of the human voltage-gated calcium channel alpha(2)delta-4 subunit. Mol. Pharmacol. 62:485-496.

22. Muth, J.N., Varadi, G., and Schwartz, A. 2001. Use of transgenic mice to study voltage-dependent Ca2+ channels. Trends Pharmacol. Sci. 22:526-532.

23. Hofmann, F., Biel, M., and Flockerzi, V. 1994. Molecular basis for $\mathrm{Ca} 2+$ channel diversity. Annu. Rev. Neurosci. 17:399-418.

24. Varadi, G., Lory, P., Schultz, D., Varadi, M., and Schwartz, A. 1991. Acceleration of activation and inactivation by the beta subunit of the skeletal muscle calcium channel. Nature. 352:159-162.

25. Sutton, K.G., Martin, D.J., Pinnock, R.D., Lee, K., and Scott, R.H. 2002. Gabapentin inhibits highthreshold calcium channel currents in cultured rat dorsal root ganglion neurones. Br. J. Pharmacol. 135:257-265

26. Marais, E., Klugbauer, N., and Hofmann, F. 2001. Calcium channel alpha(2)delta subunits-structure and Gabapentin binding. Mol. Pharmacol. 59:1243-1248.

27. Luo, Z.D., et al. 2002. Injury type-specific calcium channel alpha 2 delta-1 subunit up-regulation in rat neuropathic pain models correlates with antiallodynic effects of gabapentin. J. Pharmacol. Exp. Ther. 303:1199-1205.

28. Ivanov, S.V., et al. 2004. Cerebellar ataxia, seizures, premature death, and cardiac abnormalities in mice with targeted disruption of the Cacna2d2 gene. Am. J. Pathol. 165:1007-1018.

29. Abernethy, D.R., and Soldatov, N.M. 2002. Structure-functional diversity of human L-type Ca2+ channel: perspectives for new pharmacological targets. J. Pharmacol. Exp. Ther. 300:724-728.

30. Arikkath, J., and Campbell, K.P. 2003. Auxiliary subunits: essential components of the voltage-gated calcium channel complex. Curr. Opin. Neurobiol. 13:298-307.

31. Kang, M.G., and Campbell, K.P. 2003. Gamma subunit of voltage-activated calcium channels. J. Biol. Chem. 278:21315-21318.

32. De Waard, M., Pragnell, M., and Campbell, K.P. 1994. Ca2+ channel regulation by a conserved beta subunit domain. Neuron. 13:495-503.

33. Pragnell, M., et al. 1994. Calcium channel betasubunit binds to a conserved motif in the I-II cytoplasmic linker of the alpha 1-subunit. Nature. 368:67-70.

34. Opatowsky, Y., Chomsky-Hecht, O., Kang, M.G. Campbell, K.P., and Hirsch, J.A. 2003. The voltage-dependent calcium channel beta subunit contains two stable interacting domains. J. Biol. Chem.
278:52323-52332.

35. Van Petegem, F., Clark, K.A., Chatelain, F.C., and Minor, D.L., Jr. 2004. Structure of a complex between a voltage-gated calcium channel betasubunit and an alpha-subunit domain. Nature. 429:671-675.

36. Chen, Y.H., et al. 2004. Structural basis of the alpha1-beta subunit interaction of voltage-gated Ca2+ channels. Nature. 429:675-680.

37. Bichet, D., et al. 2000. The I-II loop of the Ca2+ channel alpha1 subunit contains an endoplasmic reticulum retention signal antagonized by the beta subunit. Neuron. 25:177-190.

38. Hanlon, M.R., Berrow, N.S., Dolphin, A.C., and Wallace, B.A. 1999. Modelling of a voltage-dependent $\mathrm{Ca} 2+$ channel beta subunit as a basis for understanding its functional properties. FEBS Lett. 445:366-370

39. McGee, A.W., et al. 2004. Calcium channel function regulated by the SH3-GK module in beta subunits. Neuron. 42:89-99.

40. Singer, D., et al. 1991. The roles of the subunits in the function of the calcium channel. Science. 253:1553-1557.

41. Muth, J.N., Bodi, I., Lewis, W., Varadi, G., and Schwartz, A. 2001. A Ca(2+)-dependent transgenic model of cardiac hypertrophy: A role for protein kinase Calpha. Circulation. 103:140-147.

42. Chien, A.J., et al. 1995. Roles of a membrane-localized beta subunit in the formation and targeting of functional L-type Ca2+ channels. J. Biol. Chem. 270:30036-30044.

43. Mikala, G., et al. 1998. cAMP-dependent phosphorylation sites and macroscopic activity of recombinant cardiac L-type calcium channels. Mol. Cell. Biochem. 185:95-109.

44. Schuhmann, K., et al. 1997. Essential role of the beta subunit in modulation of C-class L-type $\mathrm{Ca} 2+$ channels by intracellular $\mathrm{pH}$. FEBS Lett. 408:75-80.

45. Cens, T., Mangoni, M.E., Richard, S., Nargeot, J., and Charnet, P. 1996. Coexpression of the beta2 subunit does not induce voltage-dependent facilitation of the class C L-type Ca channel. Pflugers Arch. 431:771-774.

46. Tareilus, E., et al. 1997. A Xenopus oocyte beta subunit: evidence for a role in the assembly/expression of voltage-gated calcium channels that is separate from its role as a regulatory subunit. Proc. Natl. Acad. Sci. U. S. A. 94:1703-1708.

47. Yamaguchi, H., et al. 1998. Multiple modulation pathways of calcium channel activity by a beta subunit. Direct evidence of beta subunit participation in membrane trafficking of the alpha1C subunit. J. Biol. Chem. 273:19348-19356.

48. Kobrinsky, E., et al. 2005. Differential role of the alpha1C subunit tails in regulation of the Cav1.2 channel by membrane potential, beta subunits, and Ca2+ ions. J. Biol. Chem. 280:12474-12485.

49. Viard, P., et al. 2004. PI3K promotes voltage-dependent calcium channel trafficking to the plasma membrane. Nat. Neurosci. 7:939-946.

50. Gregg, R.G., et al. 1996. Absence of the beta subunit (cchb1) of the skeletal muscle dihydropyridine receptor alters expression of the alpha 1 subunit and eliminates excitation-contraction coupling. Proc. Natl. Acad. Sci. U. S. A. 93:13961-13966. 
51. Ball, S.L., et al. 2002. Role of the beta(2) subunit of voltage-dependent calcium channels in the retinal outer plexiform layer. Invest. Ophthalmol. Vis. Sci. 43:1595-1603

52. Murakami, M., et al. 2000. Conserved smooth muscle contractility and blood pressure increase in response to high-salt diet in mice lacking the beta3 subunit of the voltage-dependent calcium channel. J. Cardiovasc. Pharmacol. 36(Suppl. 2):S69-S73.

53. Hullin, R., et al. 1992. Calcium channel beta subunit heterogeneity: functional expression of cloned cDNA from heart, aorta and brain. EMBOJ. 11:885-890

54. Chien, A.J., Carr, K.M., Shirokov, R.E., Rios, E., and Hosey, M.M. 1996. Identification of palmitoylation sites within the L-type calcium channel beta2a subunit and effects on channel function. J. Biol. Chem. 271:26465-26468.

55. Qin, N., et al. 1998. Unique regulatory properties of the type $2 \mathrm{a} \mathrm{Ca2}+$ channel beta subunit caused by palmitoylation. Proc. Natl. Acad. Sci. U. S. A. 95:4690-4695.

56. Colecraft, H.M., et al. 2002. Novel functional properties of $\mathrm{Ca}(2+)$ channel beta subunits revealed by their expression in adult rat heart cells. J. Physiol. 541:435-452

57. Murakami, M., et al. 2002. Pain perception in mice lacking the beta3 subunit of voltage-activated calcium channels. J. Biol. Chem. 277:40342-40351.

58. Murakami, M., et al. 2003. Modified cardiovascular L-type channels in mice lacking the voltage-dependent Ca2+ channel beta3 subunit. J. Biol. Chem. 278:43261-43267.

59. Hullin, R., et al. 2003. Cardiac L-type calcium channel beta-subunits expressed in human heart have differential effects on single channel characteristics. J. Biol. Chem. 278:21623-21630.

60. Wei, S.K., et al. 2000. $\mathrm{Ca}(2+)$ channel modulation by recombinant auxiliary beta subunits expressed in young adult heart cells. Circ. Res. 86:175-184.

61. Groner, F., et al. 2004. Single-channel gating and regulation of human L-type calcium channels in cardiomyocytes of transgenic mice. Biochem. Biophys. Res. Commun. 314:878-884.

62. Song, L.S., et al. 2002. $\mathrm{Ca}(2+)$ signaling in cardiac myocytes overexpressing the alpha(1) subunit of L-type $\mathrm{Ca}(2+)$ channel. Circ. Res. 90:174-181.

63. Zuhlke, R.D., Pitt, G.S., Tsien, R.W., and Reuter, H. 2000. Ca2+-sensitive inactivation and facilitation of L-type Ca2+ channels both depend on specific amino acid residues in a consensus calmodulinbinding motif in the(alpha)1C subunit. J. Biol. Chem. 275:21121-21129.

64. Zuhlke, R.D., Pitt, G.S., Deisseroth, K., Tsien, R.W., and Reuter, H. 1999. Calmodulin supports both inactivation and facilitation of L-type calcium channels. Nature. 399:159-162.

65. Peterson, B.Z., DeMaria, C.D., Adelman, J.P., and Yue, D.T. 1999. Calmodulin is the Ca2+ sensor for $\mathrm{Ca} 2+$-dependent inactivation of L-type calcium channels. Neuron. 22:549-558.

66. Peterson, B.Z., et al. 2000. Critical determinants of $\mathrm{Ca}(2+)$-dependent inactivation within an EF-hand motif of L-type $\mathrm{Ca}(2+)$ channels. Biophys. $J$. 78:1906-1920.

67. Pitt, G.S., et al. 2001. Molecular basis of calmodulin tethering and Ca2+-dependent inactivation of L-type Ca2+ channels. J. Biol. Chem. 276:30794-30802.

68. Kim, J., Ghosh, S., Nunziato, D.A., and Pitt, G.S. 2004. Identification of the components controlling inactivation of voltage-gated $\mathrm{Ca} 2+$ channels. Neuron. 41:745-754.

69. Yang, D., et al. 2003. Calmodulin regulation of excitation-contraction coupling in cardiac myocytes. Circ. Res. 92:659-667.

70. Dzhura, I., Wu, Y., Colbran, R.J., Balser, J.R., and Anderson, M.E. 2000. Calmodulin kinase determines calcium-dependent facilitation of L-type calcium channels. Nat. Cell Biol. 2:173-177.

71. Zhang, R., et al. 2005. Calmodulin kinase II inhibition protects against structural heart disease. Nat. Med. 11:409-417.

72. Anderson, M.E. 2004. Calmodulin kinase and L-type calcium channels; a recipe for arrhythmias? Trends Cardiovasc. Med. 14:152-161.

73. Tessier, S., et al. 1999. Regulation of the transient outward $\mathrm{K}(+)$ current by $\mathrm{Ca}(2+) /$ calmodulin-dependent protein kinases II in human atrial myocytes. Circ. Res. 85:810-819.

74. Anderson, M.E. 2005. Calmodulin kinase signaling in heart: an intriguing candidate target for therapy of myocardial dysfunction and arrhythmias. Pharmacol. Ther 106:39-55.

75. Muller, F.U., Neumann, J., and Schmitz, W. 2000. Transcriptional regulation by cAMP in the heart. Mol. Cell. Biochem. 212:11-17.

76. Echt, D.S., et al. 1991. Mortality and morbidity in patients receiving encainide, flecainide, or placebo. The Cardiac Arrhythmia Suppression Trial. N. Engl. J. Med. 324:781-788.

77. Packer, M., et al. 1996. Effect of amlodipine on morbidity and mortality in severe chronic heart failure. Prospective Randomized Amlodipine Survival Evaluation Study Group. N. Engl. J. Med. 335:1107-1114.

78. Boden, W.E., et al. 1996. Rationale and design of the Third Vasodilator-Heart Failure Trial (V-HeFT III): felodipine as adjunctive therapy to enalapril and loop diuretics with or without digoxin in chronic congestive heart failure. V-HeFT III investigators. Am. J. Cardiol. 77:1078-1082.

79. Dunselman, P.H., et al. 1989. Efficacy of felodipine in congestive heart failure. Eur. Heart J. 10:354-364

80. Elkayam, U., et al. 1990. A prospective, randomized, double-blind, crossover study to compare the efficacy and safety of chronic nifedipine therapy with that of isosorbide dinitrate and their combination in the treatment of chronic congestive heart failure. Circulation. 82:1954-1961.

81. Furberg, C.D., Psaty, B.M., and Meyer, J.V. 1995. Nifedipine. Dose-related increase in mortality in patients with coronary heart disease. Circulation. 92:1326-1331.

82. [Anonymous]. 1992. Improved diastolic function with the calcium antagonist nisoldipine (coatcore) in patients post myocardial infarction: results of the DEFIANT study. Doppler Flow and Echocardiography in Functional Cardiac Insufficiency: Assessment of Nisoldipine Therapy. Eur. Heart J. 13:1496-1505.

83. [Anonymous]. 1990. Effect of verapamil on mortality and major events after acute myocardial infarction (the Danish Verapamil Infarction Trial II-DAVIT II). Am. J. Cardiol. 66:779-785.

84. Black, H.R., et al. 2003. Principal results of the Controlled Onset Verapamil Investigation of Cardiovascular End Points (CONVINCE) trial. JAMA. 289:2073-2082.

85. [Anonymous]. 1988. The effect of diltiazem on mortality and reinfarction after myocardial infarction. The Multicenter Diltiazem Postinfarction Trial Research Group. N. Engl. J. Med. 319:385-392.

86. Kostis, J.B., Lacy, C.R., Cosgrove, N.M., and Wilson, A.C. 1997. Association of calcium channel blocker use with increased rate of acute myocardial infarction in patients with left ventricular dysfunction. Am. Heart J. 133:550-557.

87. Ibrahim, O.A., and Dunlap, M.E. 2005. Combination pharmacologic therapies for heart failure: what next after angiotensin-converting enzyme inhibitors and beta-blockers? Curr. Heart Fail. Rep. 2:89-93

88. He, M., Bodi, I., Mikala, G., and Schwartz, A. 1997. Motif III S5 of L-type calcium channels is involved in the dihydropyridine binding site. A combined radioligand binding and electrophysiological study. J. Biol. Chem. 272:2629-2633.

89. Hockerman, G.H., Johnson, B.D., Abbott, M.R., Scheuer, T., and Catterall, W.A. 1997. Molecular determinants of high affinity phenylalkylamine block of L-type calcium channels in transmembrane segment IIIS6 and the pore region of the alpha1 subunit. J. Biol. Chem. 272:18759-18765.

90. Hering, S., et al. 1996. Transfer of high sensitivity for benzothiazepines from L-type to class A (BI) calcium channels. J. Biol. Chem. 271:24471-24475.

91. Schuster, A., et al. 1996. The IVS6 segment of the L-type calcium channel is critical for the action of dihydropyridines and phenylalkylamines. EMBO J. 15:2365-2370

92. Hockerman, G.H., Johnson, B.D., Scheuer, T., and Catterall, W.A. 1995. Molecular determinants of high affinity phenylalkylamine block of L-type calcium channels. J. Biol. Chem. 270:22119-22122.

93. Starmer, C.F., Grant, A.O., and Strauss, H.C. 1984 Mechanisms of use-dependent block of sodium channels in excitable membranes by local anesthetics. Biophys. J. 46:15-27.

94. Hering, S., Berjukow, S., Aczel, S., and Timin, E.N. 1998. Ca2+ channel block and inactivation: common molecular determinants. Trends Pharmacol. Sci. 19:439-443.

95. Hering, S., et al. 1997. Molecular mechanism of use-dependent calcium channel block by phenylalkylamines: role of inactivation. Proc. Natl. Acad. Sci. U. S. A. 94:13323-13328

96. Motoike, H.K., Bodi, I., Nakayama, H., Schwartz, A., and Varadi, G. 1999. A region in IVS5 of the human cardiac L-type calcium channel is required for the use-dependent block by phenylalkylamines and benzothiazepines. J. Biol. Chem. 274:9409-9420.

97. Benitah, J.P., et al. 2002. Voltage-gated Ca2+ currents in the human pathophysiologic heart: a review. Basic Res. Cardiol. 97(Suppl. 1):I11-I18.

98. Haase, H., et al. 1996. Expression of calcium channel subunits in the normal and diseased human myocardium. J. Mol. Med. 74:99-104.

99. Hullin, R., Asmus, F., Ludwig, A., Hersel, J., and Boekstegers, P. 1999. Subunit expression of the cardiac L-type calcium channel is differentially regulated in diastolic heart failure of the cardiac allograft. Circulation. 100:155-163.

100.Schroder, F., et al. 1998. Increased availability and open probability of single L-type calcium channels from failing compared with nonfailing human ventricle. Circulation. 98:969-976.

101.Bosch, R.F., et al. 2003. Molecular mechanisms of early electrical remodeling: transcriptional downregulation of ion channel subunits reduces $\mathrm{I}(\mathrm{Ca}, \mathrm{L})$ and $\mathrm{I}(\mathrm{to})$ in rapid atrial pacing in rabbits. J. Am. Coll. Cardiol. 41:858-869.

102.Schotten, U., et al. 2003. The L-type Ca2+-channel subunits alpha1C and beta 2 are not downregulated in atrial myocardium of patients with chronic atrial fibrillation. J. Mol. Cell. Cardiol. 35:437-443.

103. Bosch, R.F., et al. 1999. Ionic mechanisms of electrical remodeling in human atrial fibrillation. Cardiovasc. Res. 44:121-131.

104.Van Wagoner, D.R., et al. 1999. Atrial L-type Ca2+ currents and human atrial fibrillation. Circ. Res. 85:428-436.

105.Christ, T., et al. 2004. L-type Ca2+ current downregulation in chronic human atrial fibrillation is associated with increased activity of protein phosphatases. Circulation. 110:2651-2657.

106. Brundel, B.J., et al. 2001. Ion channel remodeling is related to intraoperative atrial effective refractory periods in patients with paroxysmal and persistent atrial fibrillation. Circulation. 103:684-690.

107. Klein, G., et al. 2003. Increased open probability of single cardiac L-type calcium channels in patients with chronic atrial fibrillation. Role of phosphatase $2 \mathrm{~A}$. 
Cardiovasc. Res. 59:37-45.

108.He, J., et al. 2001. Reduction in density of transverse tubules and $\mathrm{L}$-type $\mathrm{Ca}(2+)$ channels in canine tachycardia-induced heart failure. Cardiovasc. Res. 49:298-307.

109.Boixel, C., Gonzalez, W., Louedec, L., and Hatem, S.N. 2001. Mechanisms of L-type $\mathrm{Ca}(2+)$ current downregulation in rat atrial myocytes during heart failure. Circ. Res. 89:607-613.

110.Yang, Y., et al. 2000. L-type Ca2+ channel alpha 1c subunit isoform switching in failing human ventricular myocardium. J. Mol. Cell. Cardiol. 32:973-984.

111.Splawski, I., et al. 2004. Ca(V)1.2 calcium channel dysfunction causes a multisystem disorder including arrhythmia and autism. Cell. 119:19-31.

112. Gomez, A.M., et al. 1997. Defective excitation-contraction coupling in experimental cardiac hypertrophy and heart failure. Science. 276:800-806.

113. Beuckelmann, D.J., Nabauer, M., and Erdmann, E. 1992. Intracellular calcium handling in isolated ventricular myocytes from patients with terminal heart failure. Circulation. 85:1046-1055.

114.Beuckelmann, D.J., and Wier, W.G. 1988. Mechanism of release of calcium from sarcoplasmic reticulum of guinea-pig cardiac cells. J. Physiol. 405:233-255.

115.Wier, W.G., Egan, T.M., Lopez-Lopez, J.R., and Balke, C.W. 1994. Local control of excitationcontraction coupling in rat heart cells. J. Physiol. 474:463-471.

116. Hobai, I.A., and O'Rourke, B. 2001. Decreased sarcoplasmic reticulum calcium content is responsible for defective excitation-contraction coupling in canine heart failure. Circulation. 103:1577-1584.

117. Pogwizd, S.M., Schlotthauer, K., Li, L., Yuan, W., and Bers, D.M. 2001. Arrhythmogenesis and contractile dysfunction in heart failure: Roles of sodium-calcium exchange, inward rectifier potassium current, and residual beta-adrenergic responsiveness. Circ. Res. 88:1159-1167.

118.Lindner, M., et al. 2002. Calcium sparks in human ventricular cardiomyocytes from patients with terminal heart failure. Cell Calcium. 31:175-182.

119.Lindner, M., Erdmann, E., and Beuckelmann, D.J. 1998. Calcium content of the sarcoplasmic reticulum in isolated ventricular myocytes from patients with terminal heart failure. J. Mol. Cell. Cardiol. 30:743-749.
120.Sjaastad, I., Wasserstrom, J.A., and Sejersted, O.M. 2003. Heart failure - a challenge to our current concepts of excitation-contraction coupling. J. Physiol. 546:33-47.

121. Shorofsky, S.R., et al. 1999. Cellular mechanisms of altered contractility in the hypertrophied heart: big hearts, big sparks. Circ. Res. 84:424-434.

122. Marx, S.O., et al. 2000. PKA phosphorylation dissociates FKBP12.6 from the calcium release channel (ryanodine receptor): defective regulation in failing hearts. Cell. 101:365-376.

123. Reuter, H., Han, T., Motter, C., Philipson, K.D., and Goldhaber, J.I. 2004. Mice overexpressing the cardiac sodium-calcium exchanger: defects in excitation-contraction coupling. J. Physiol. 554:779-789.

124. Henderson, S.A., et al. 2004. Functional adult myocardium in the absence of $\mathrm{Na}^{+-} \mathrm{Ca} 2+$ exchange: cardiac-specific knockout of NCX1. Circ. Res. 95:604-611.

125.Grandy, S.A., Denovan-Wright, E.M., Ferrier, G.R., and Howlett, S.E. 2004. Overexpression of human beta2-adrenergic receptors increases gain of excitation-contraction coupling in mouse ventricular myocytes. Am. J. Physiol. Heart Circ. Physiol. 287:H1029-H1038. 